\title{
Fatores de estresse associados à criação de linhagens de avós de frangos de corte
}

\section{Marco Aurélio Neves da Silva ${ }^{1}$, José Antonio Delfino Barbosa Filho ${ }^{2}$, Millor Fernandes do Rosário ${ }^{3}$, Caio José Mortari da Silva ${ }^{4}$, Iran José Oliveira da Silva ${ }^{5}$, Vicente José Maria Savino ${ }^{6}$, Antonio Augusto Domingos Coelho ${ }^{6}$}

\author{
${ }^{1}$ Doutorando (Bolsista CAPES) - Núcleo de Pesquisa em Ambiência (NUPEA) - Departamento de Genética - ESALQ/USP - Av. Pádua Dias, \\ 11. Cp. 83. CEP: 13400-970. Piracicaba/SP/Brasil. \\ 2 Doutorando (Bolsista FAPESP) - NUPEA - Departamento de Engenharia Rural - ESALQ/USP \\ ${ }^{3}$ Doutorando (Bolsista FAPESP) - Departamento de Genética - ESALQ/USP. \\ ${ }^{4}$ Iniciação Científica - NUPEA - Departamento de Genética - ESALQ/USP. \\ ${ }^{5}$ NUPEA - Departamento de Engenharia Rural - ESALQ/USP. \\ ${ }^{6}$ Departamento de Genética - ESALQ/USP.
}

RESUMO - Objetivou-se avaliar o desempenho e a variabilidade entre linhagens de avós de frangos de corte criadas em diferentes ambientes, considerando a interação genótipo $\times$ ambiente. Foram conduzidos 12 experimentos (quatro em ambiente de criação de frangos de corte, quatro em ambiente de criação sob condições de estresse e quatro em ambiente de granja de pedigree) utilizando-se 36.000 pintos (3.000 por experimento) de seis linhagens de avós de frangos de corte (quatro de linha fêmea e duas de linha macho), criados até a idade de 42 dias para avaliação de variáveis zootécnicas e morfométricas. Foram utilizados índices de conforto térmico (índice de temperatura e umidade e entalpia) para avaliação do microclima interno das instalações a que as aves foram expostas. Realizaram-se comparações de médias das características zootécnicas (peso vivo e rendimento de carcaça) e morfométricas (empenamento) das linhagens criadas nos diferentes ambientes. As respostas das linhagens para as características avaliadas variaram conforme o ambiente de criação utilizado. As linhagens da linha macho apresentaram maiores pesos vivos e rendimentos de carcaça eviscerada em comparação às da linha fêmea, que apresentaram melhor empenamento do dorso e da perna.

Palavras-chave: empenamento, peso vivo, rendimento de carcaça, seleção

\section{Environmental influence on the performance of parental lines of broiler chicken}

\begin{abstract}
The aim of this study was to evaluate the performance and the variability between parental lines of broiler chicken reared in different environments, considering the genotype and environment interaction. Performance and morphometric traits of parental lines of commercial broiler chicken reared up to the age of 42 days in a complete-controlled environment of a breeding farm, in usual conditions of broiler chicken production system and in stress environment conditions were evaluated. Indexes of thermal comfort (temperature and humidity and enthalpy) were used to evaluate the internal microclimate of the instalations, where the birds were reared. Comparison of averages of performance (body weight and carcass yield) and morphometric (back and leg featherings) traits of parental lines indicated they differed according to the rearing environment. Body weight and carcass yield were higher for male than for female lines, which presented better back and leg feathering than the male lineages.
\end{abstract}

Key Words: feathering, body weight, carcass yield, selection

\section{Introdução}

O melhoramento genético de linhagens avícolas tem contribuído para a crescente eficiência da avicultura brasileira. No entanto, para a seleção de genótipos superiores em programas de melhoramento, são necessárias avaliações da variabilidade existente associadas à criação em diferentes ambientes.
O ambiente pode ser definido como a soma dos impactos circundantes biológicos e físicos. Assim, variáveis ambientais como temperatura, umidade relativa, ventilação e radiação solar são importantes indicadores da qualidade do ambiente para a ave por serem agentes estressores e que podem afetar o metabolismo (Macari et al., 2004).

Souza \& Michelan Filho (2004) citaram que o progresso na criação do frango de corte está relacionado a importantes 
características de desempenho do híbrido comercial, como peso vivo e conformação de carcaça, e, uma vez que o ambiente pode influenciar o desempenho das aves, é essencial que o efeito das variáveis ambientais seja considerado nos sistemas de produção e seleção genética.

Quando as aves são submetidas a estresse, processos fisiológicos são ativados para manutenção da homeotermia corporal, reduzindo a energia destinada à produção (Macari et al., 2004; Yahav et al., 2005).

As aves apresentam melhor desempenho produtivo quando criadas na zona termoneutra ou de conforto térmico, ou seja, em ambientes com faixa de temperatura em que a taxa metabólica é mínima e a homeotermia é mantida com menos gasto energético (Furlan \& Macari, 2002).

Mudanças no ambiente de criação que diminuam as condições de estresse podem melhorar o conforto do animal, seu bem-estar e, conseqüentemente, a produção (Jones et al., 2005). Estudos na área de genética têm sido realizados visando ao desenvolvimento de aves com melhor adaptabilidade aos ambientes de criação e à melhora dos índices zootécnicos (Silva et al., 2001).

Este estudo foi realizado para avaliar a influência ambiental em características morfométricas e zootécnicas de linhagens de aves de corte criadas em diferentes ambientes.

\section{Material e Métodos}

Foram conduzidos oito experimentos no Setor de Aves do Departamento de Genética da Escola Superior de Agricultura Luiz de Queiroz, em Piracicaba-SP. Quatro experimentos foram realizados em ambiente de criação de frangos de corte e quatro em ambiente de criação sob condições de estresse no período de agosto de 2003 a setembro de 2004. Nesse mesmo período, foram realizados ainda quatro experimentos em instalações comercias de empresa avícola em Itirapina - SP, em ambiente de granja de pedigree.

Utilizaram-se 36.000 pintos (3.000 por experimento) de seis linhagens de avós de frangos de corte - quatro de linha fêmea (LF1, LF2, LF3 e LF4) e duas de linha macho (LM1 e LM2) - utilizadas em cruzamentos para obtenção de uma linhagem comercial amplamente utilizada na avicultura brasileira.

Como ambiente de criação, consideraram-se todas as condições físicas das instalações, os sistemas de controle do microclima interno, as condições de manejo e equipamentos e as condições de nutrição e sanidade adotadas em cada tipo de criação. Os experimentos em ambiente de granja de pedigree foram realizados em galpão de alvenaria com piso de cimento ( 14 x $156 \mathrm{~m}$ ), 3,5 m de pé-direito e uma porta hermética, única abertura do galpão. O controle das variáveis ambientais do microclima interno, como temperatura, umidade e ventilação, foi feito por meio de ventilação forçada por painéis evaporativos e exaustores, evitando-se qualquer influência do microclima externo ao galpão. Além do controle ambiental, efetuou-se o controle sanitário para evitar qualquer tipo de contaminação ou desafio às aves.

As aves foram alojadas no respectivo experimento, sem separação de sexo, em seis boxes com cama de maravalha (um para cada linhagem), com taxa de lotação de 10 aves $/ \mathrm{m}^{2}$.

Do nascimento aos 10 dias de idade, foram utilizadas campânulas a gás, uma por boxe, para aquecimento das aves. Do $1 \underline{0}$ ao 3으 dia de alojamento, o programa de luz

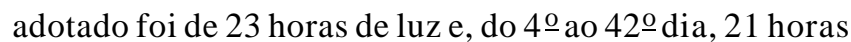
de luz. Até o 7ํㅡ dia de idade, foram utilizados bebedouros do tipo pressão e comedouros tubulares (um de cada tipo para cada 80 aves) e, a partir do 80 dia, utilizaram-se bebedouros do tipo nipple (um bico para cada dez aves) e comedouro automático de corrente (1 $\mathrm{m}$ de calha para 40 aves).

No ambiente de criação de frangos de corte, utilizou-se galpão comercial de alvenaria, com piso de cimento (10 x 60m) e 3,5 m de pé-direito, com aberturas laterais teladas e portas comuns. Além da ventilação natural, controlada por meio das cortinas laterais do galpão, utilizaram-se ventiladores e nebulizadores para controle das variáveis ambientais internas, como temperatura e umidade. Nesse ambiente de criação, o microclima interno dos galpões podia sofrer influência do microclima externo.

A densidade de alojamento utilizada (12 aves $\left./ \mathrm{m}^{2}\right)$ foi maior que a adotada no ambiente de pedigree, para maior alojamento de quilograma de peso vivo $/ \mathrm{m}^{2}$. As aves foram alojadas em seis boxes com cama de casca de arroz e, desde o nascimento até os dez primeiros dias de idade, foram mantidas sob aquecimento com lâmpadas de infravermelho (250 watts) na proporção de uma por boxe.

Do $1 \underline{0}$ ao $7 \underline{0}$ dia de alojamento, foram utilizados bebedouros do tipo pressão e comedouros tubulares na proporção de um para cada 80 aves. A partir do $8^{\circ}$ o dia, a água e a dieta foram fornecidas em bebedouros do tipo pendular e comedouros tubulares tipo adulto, na proporção de um para cada 80 e 40 aves, respectivamente. O programa de luz adotado foi de 24 horas nos dez primeiros dias de alojamento e de 21 horas de luz do 11 o ao $42 \underline{o}$ dia.

$\mathrm{O}$ ambiente de estresse baseou-se no princípio de que as aves deveriam ser expostas a todas as condições de desafios possíveis, desde alta densidade de alojamento e de aves por equipamento de manejo até ausência de equi- 
pamentos para controle de variáveis ambientais como temperatura e umidade, sofrendo grande influência das condições climáticas externas às instalações.

Os experimentos nesse ambiente de criação foram realizados em galpão de alvenaria com piso de cimento $(10 \times 60 \mathrm{~m})$ e 3,5 m de pé-direito, com aberturas laterais teladas e portas comuns. As aves foram alojadas, sem separação de sexo, em seis boxes (um por linhagem) com cama de maravalha, em densidade de 15 aves $/ \mathrm{m}^{2}$. Do $1{ }^{\circ}$ ao 10 o dia de alojamento, as aves foram mantidas sob aquecimento com campânulas a gás, na proporção de uma/boxe. No 1 dia de alojamento, o programa de luz adotado foi de 24 horas de luz e, do $2{ }^{\circ}$ ao $42^{\circ}$ dia, de 20 horas de luz.

Até $\mathrm{o}$ 70 dia de alojamento, foram utilizados bebedouros do tipo pressão e comedouros tubulares (um para cada 100 aves) e, a partir do 8 o dia, utilizaram-se bebedouros do tipo pendular (um para 120 aves) e comedouros automáticos de corrente na proporção de $1 \mathrm{~m}$ de calha para 75 aves.

Todas as aves foram vacinadas ao nascer contra a doença de Marek, Gumboro, Newcastle e bouba aviária, sendo aneladas com código de barra e alojadas nos respectivos experimentos. As aves foram vacinadas também na água de bebida, aos 10 e 18 dias de idade, contra as doenças de Newcastle, Gumboro e bronquite infecciosa, conforme recomendação do fabricante das vacinas.

A dieta e a água foram fornecidas ad libitum durante todo o período de criação, que se estendeu até 42 dias de idade em todos os experimentos. As aves mortas ou com problemas foram retiradas ou descartadas diariamente de todos os experimentos.

Os tipos de dieta e as idades de fornecimento para as aves dos três diferentes ambientes de criação são descritos na Tabela 1 . Todas as dietas foram formuladas com ingredientes básicos como milho moído, farelo de soja, óleo de soja, calcário e premix específico para cada fase de crescimento.

Os dados de temperatura de bulbo seco (Tbs), temperatura de bulbo úmido (Tbu) e umidade relativa (UR) foram coletados por meio de termohigrômetros instalados no interior dos galpões para avaliação, a partir dos índices de conforto térmico THI e entalpia, do microclima interno a que as aves foram expostas. Esses índices foram avaliados nos três ambientes de criação, após a retirada das fontes artificiais de aquecimento das aves (10o dia de criação).

Tabela 1 - Características e tipos de dietas utilizadas em cada ambiente de criação Table 1 - Traits and diet types used in each rearing environment

\begin{tabular}{|c|c|c|c|c|c|}
\hline \multirow[t]{2}{*}{$\begin{array}{l}\text { Ambiente de criação } \\
\text { Rearing environment }\end{array}$} & \multirow[t]{2}{*}{$\begin{array}{c}\text { Característica } \\
\text { Trait }\end{array}$} & \multicolumn{4}{|c|}{$\begin{array}{l}\text { Tipo de dieta } \\
\text { Diet type }\end{array}$} \\
\hline & & $\begin{array}{l}\text { Pré-inicial } \\
\text { Pre-starter }\end{array}$ & $\begin{array}{l}\text { Inicial } \\
\text { Starter }\end{array}$ & $\begin{array}{l}\text { Crescimento } \\
\text { Growth }\end{array}$ & $\begin{array}{c}\text { Final } \\
\text { Finishing }\end{array}$ \\
\hline \multirow{7}{*}{$\begin{array}{l}\text { Pedigree } \\
\text { Pedigree }\end{array}$} & Idade de fornecimento (dias) & $0-11$ & $12-21$ & $22-42$ & - \\
\hline & Catering age (days) & & & & \\
\hline & Tipo de granulometria & Triturada & Triturada & Triturada & - \\
\hline & $\begin{array}{l}\text { Particle size type } \\
\text { PB }(\%)\end{array}$ & $\begin{array}{c}\text { Ground } \\
22,0\end{array}$ & $\begin{array}{c}\text { Ground } \\
21,1\end{array}$ & $\begin{array}{c}\text { Ground } \\
19,2\end{array}$ & - \\
\hline & $C P(\%)$ & & & & \\
\hline & EM $(\mathrm{kcal} / \mathrm{kg})$ & 3.000 & 3080 & 3180 & - \\
\hline & $M E(\mathrm{kcal} / \mathrm{kg})$ & & & & \\
\hline \multirow[t]{6}{*}{$\begin{array}{l}\text { Frango de corte } \\
\text { Broiler }\end{array}$} & $\begin{array}{l}\text { Idade de fornecimento (dias) } \\
\text { Catering age (days) }\end{array}$ & $0-11$ & $12-21$ & $22-35$ & $36-42$ \\
\hline & Tipo de granulometria & Farelada & Farelada & Farelada & Farelada \\
\hline & $\begin{array}{l}\text { Particle size type } \\
\mathrm{PB}(\%)\end{array}$ & $\begin{array}{l}\text { Powdered } \\
23,0\end{array}$ & $\begin{array}{l}\text { Powdered } \\
22,0\end{array}$ & $\begin{array}{l}\text { Powdered } \\
20,0\end{array}$ & $\begin{array}{l}\text { Powdered } \\
20,0\end{array}$ \\
\hline & $C P(\%)$ & & & & \\
\hline & EM $(\mathrm{kcal} / \mathrm{kg})$ & 3.000 & 3.080 & 3.180 & 3.260 \\
\hline & $M E(k c a l / k g)$ & & & & \\
\hline \multirow{8}{*}{$\begin{array}{l}\text { Estresse } \\
\text { Stress }\end{array}$} & Idade de fornecimento (dias) & - & $0-21$ & - & $22-42$ \\
\hline & Catering age (days) & & & & \\
\hline & Tipo de granulometria & - & Farelada & - & Farelada \\
\hline & Particle size type & & Powdered & & Powdered \\
\hline & $\mathrm{PB}(\%)$ & - & 20,4 & - & 17,5 \\
\hline & $C P(\%)$ & & & & \\
\hline & EM (kcal/kg) & - & 2.950 & - & 3.050 \\
\hline & $M E(\mathrm{kcal} / \mathrm{kg})$ & & & & \\
\hline
\end{tabular}

\footnotetext{
${ }^{1}$ Triturada: $\mathrm{DGM}=1,2 \mathrm{~mm}$; Farelada: $\mathrm{DGM}=0,8 \mathrm{~mm}$
}

${ }^{1}$ Ground: $A G D=1.2 \mathrm{~mm}$; Powdered: $A G D=0.8 \mathrm{~mm}$. 
Realizaram-se as avaliações diárias em intervalos duas horas, das 7 às $15 \mathrm{~h}$, do 11 o ao 42 o dia de criação das aves.

Desenvolvido inicialmente para humanos (Thom, 1958), o THI tem sido amplamente utilizado na agropecuária por englobar os efeitos combinados de temperatura de bulbo seco e bulbo úmido. A equação para cálculo deste índice é apresentada a seguir:

$$
\mathrm{THI}=\mathrm{Tbs}+0,36 \times \mathrm{Tbu}+41,5
$$

em que $\mathrm{THI}=\mathrm{em}^{\circ} \mathrm{C} ; \mathrm{Tbs}=$ temperatura de bulbo seco, em ${ }^{\circ} \mathrm{C}$; e Tbu = temperatura de bulbo úmido, em ${ }^{\circ} \mathrm{C}$.

A entalpia, definida como a energia do ar úmido por unidade de massa de ar seco $(\mathrm{kJ} / \mathrm{kg}$ ar seco), foi calculada por meio da equação descrita por Villa Nova (1999), citado por Barbosa Filho et al. (2006), apresentada a seguir:

$$
\begin{aligned}
& \mathrm{H}=6,7+0,243 \times \mathrm{Tbs}+\left\{\mathrm{UR} / 100 \times 10^{[(7,5 \times \mathrm{Tbs}) /(237,3+}\right. \\
& \text { Tbs)] }
\end{aligned}
$$

em que $\mathrm{H}=$ entalpia, em $\mathrm{kcal} / \mathrm{kg}$ de ar seco; $\mathrm{Tbs}=$ temperatura de bulbo seco, em ${ }^{\circ} \mathrm{C}$; e UR = umidade relativa, em \%.

Utilizou-se a conversão do valor da entalpia de $\mathrm{kcal} / \mathrm{kg}$ de ar seco para $\mathrm{kJ} / \mathrm{kg}$ de ar seco para facilitar sua apresentação.

Aos 28 dias de idade, foram obtidas ao acaso 50 aves de cada linhagem, em cada experimento, de cada ambiente, para avaliação das características morfométricas empenamento do dorso e da perna. Adotou-se para esta avaliação um escore de 0 a 10 , em que 0 corresponde a dorso e pernas totalmente desprovidos de penas e 10 corresponde a dorso e pernas totalmente cobertos por penas.

Ao completarem 42 dias de idade, foram selecionadas 50 aves de cada linhagem, de cada experimento, em cada ambiente, para avaliação do peso vivo e dez aves para avaliação de rendimento de carcaça após abate. O rendimento de carcaça correspondeu à porcentagem do peso da carcaça eviscerada, sem cabeça, pescoço, pés e gordura abdominal, em relação ao peso vivo.

Inicialmente, foi realizada a análise conjunta dos quatro experimentos realizados em épocas diferentes em cada ambiente de criação no intuito de verificar a existência de diferenças significativas entre experimentos conduzidos no mesmo ambiente. Essas diferenças não foram verificadas e, por isso, optou-se por considerar os dados obtidos nos quatro experimentos de cada ambiente como um só experimento, aumentando, desta forma, o número total de repetições.

Empregou-se o delineamento inteiramente ao acaso, em esquema fatorial 6 x 3 (linhagens x ambientes de criação), com 200 repetições para as características empenamento do dorso e da perna aos 28 dias de idade e peso vivo aos 42 dias de idade e com 40 repetições para a variável rendimento da carcaça aos 42 dias de idade. Considerou-se a ave como unidade experimental.

O modelo estatístico utilizado foi o seguinte:

$$
\mathrm{Y}_{i j l}=\mu+\alpha_{i}+\tau_{j}+(\alpha \tau)_{i j}+\varepsilon_{i j l}
$$

em que $\mathrm{Y}_{i j l}=$ valor observado da $i$-ésima linhagem, no $j$-ésimo ambiente de criação, na $l$-ésima repetição; $\mu=$ média geral; $\alpha_{i}=$ efeito da $i$-ésima linhagem; $i=1, \ldots, 6$; $\tau_{j}=$ efeito do $j$-ésimo ambiente de criação; $j=1,2,3$; $(\alpha \tau)_{i j}=$ efeito da interação entre a $i$-ésima linhagem e o j-ésimo ambiente de criação; $\varepsilon_{i j l}=$ erro associado a cada observação, assumindo $\mathrm{e}_{i j l} \sim \operatorname{NID}\left(0, \sigma^{2}\right)$.

As análises de variância das variáveis-respostas foram realizadas utilizando-se o programa $\mathrm{SAS}^{\circledR}$ versão 8.02 (2005), procedimento GLM, considerando um modelo fixo para todas as fontes de variação. Foram obtidas as médias ajustadas dos efeitos fixos por quadrados mínimos por meio do comando LSMEANS (least square means) e as comparações de médias foram realizadas por meio do teste Tukey $(\mathrm{P}<0,05)$.

\section{Resultados e Discussão}

Na Figura 1 são apresentados os valores médios dos índices de temperatura e umidade (THI), obtidos a partir dos valores médios de THI dos três ambientes de criação no período de 11 a 42 dias de idade, bem como os limites inferior (LI) e superior (LS) $\left(71\right.$ e $75^{\circ} \mathrm{C}$, respectivamente) da faixa de conforto para as aves (Barbosa Filho, 2004).

No horário inicial, apenas no ambiente de pedigree encontraram-se valores médios de THI dentro da faixa de conforto para as aves, enquanto, nos ambientes de criação de frango de corte e de estresse, os valores de THI ficaram abaixo do limite inferior $\left(71^{\circ} \mathrm{C}\right)$, caracterizando condição de estresse térmico pelo frio, que, segundo Macari et al. (2004), desencadeia nas aves mecanismos fisiológicos como vasoconstrição periférica e aumento de metabolismo para manutenção da temperatura corpórea.

A partir de 11h, os valores médios do THI dos ambientes de criação de frango de corte e de estresse permaneceram acima do limite superior da zona de conforto $\left(75^{\circ} \mathrm{C}\right)$, caracterizando uma condição de estresse por calor para as aves, enquanto, no ambiente de pedigree, os valores de THI mantiveram-se na zona de conforto.

No ambiente de pedigree, observaram-se por mais tempo, ao longo do período dos dias avaliados, valores de THI dentro da zona de conforto para as aves, enquanto, nos ambientes de criação de frango de corte e de estresse, os valores mantiveram-se fora dessa zona por mais tempo. 


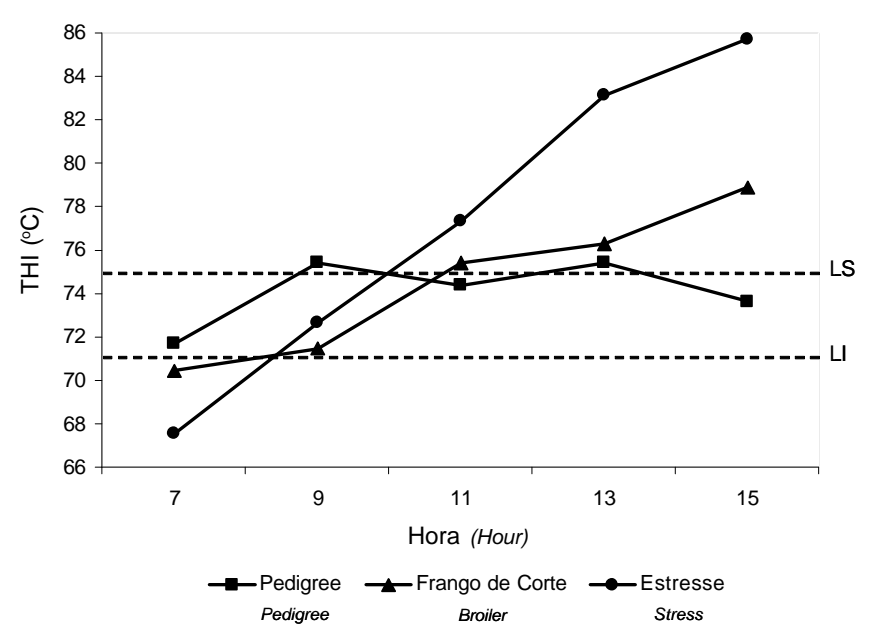

Figura 1 - Valores médios do índice de temperatura e umidade (THI) nos três ambientes de criação no período de 11 a 42 dias de idade. Limites inferior (LI) e superior (LS) da faixa de conforto térmico para as aves.

Figure 1 - Average values for temperature and humidity index (THI) in the three rearing environments from 11 to 42 days of age; lower (IL) and upper limits (SL) of the range considered to be thermal comfort for birds.

Portanto, os equipamentos de climatização instalados no ambiente de frango de corte não possibilitaram condicionamento ambiental eficiente nas horas mais quentes do dia.

Os comportamentos da entalpia nos três ambientes de criação são apresentados na Figura 2, assim como os limites inferior (LI) e superior (LS) $(64$ e $70 \mathrm{~kJ} / \mathrm{kg}$ de ar seco, respectivamente) da faixa de conforto considerados ideais para as aves segundo Barbosa Filho (2004).

No ambiente de pedigree, os valores médios de entalpia permaneceram abaixo do limite inferior da zona de conforto para as aves durante todo o período avaliado. No ambiente de frango de corte, os valores médios de entalpia ficaram na zona de conforto somente às $15 \mathrm{~h} \mathrm{e}$, no ambiente de estresse, às $11 \mathrm{~h}$. O ambiente de estresse, às 13 e 15h, proporcionou valores médios de entalpia superiores ao limite superior da zona de conforto.

Segundo Nääs et al. (2001), o uso de avaliações ambientais permite a determinação do reflexo do desconforto no lote de aves em decorrência de situações completamente adversas à zona de conforto térmico. Uma vez que os índices de conforto térmico (THI e entalpia) obtidos no ambiente de estresse permaneceram por mais tempo fora da zona de conforto para as aves, pode-se considerar que foram bem caracterizadas situações inadequadas e mais estressantes para criação que as encontradas nos ambientes de pedigree e de frango de corte.

A análise de variância (Tabela 2) evidenciou diferenças significativas para todas as variáveis (empenamento do dorso e da perna aos 28 dias de idade e peso vivo e

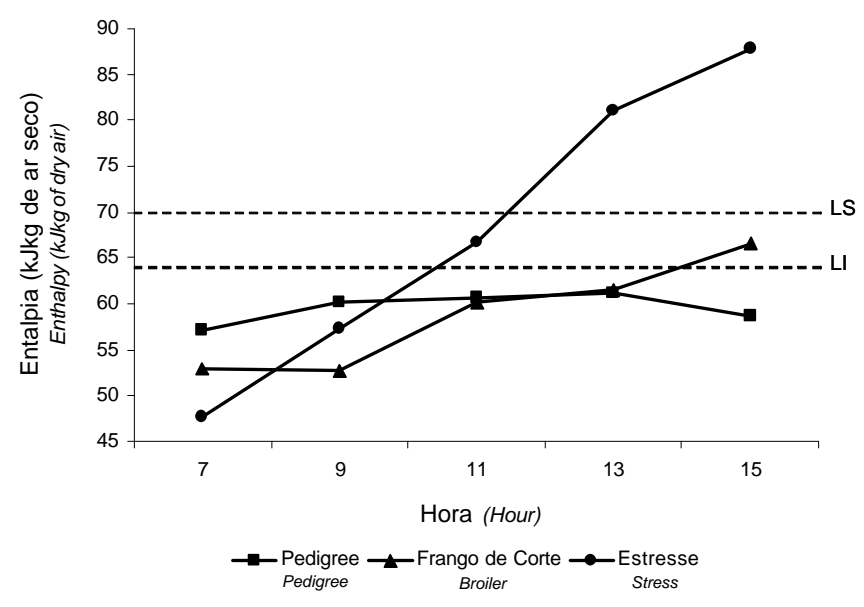

Figura 2 - Valores médios de entalpia nos três ambientes de criação no período de 11 a 42 dias de idade. Limites inferior (LI) e superior (LS) da faixa de conforto térmico para as aves.

Figure 2 - Average enthalpy values in the three rearing environment from 11 to 42 days of age; lower (IL) and upper limits (SL) of the range considered to be thermal comfort for birds.

rendimento da carcaça aos 42 dias) nas comparações entre ambientes de criação (A), linhagens (L) e interação (A x L).

As linhagens LF3 e LF4 apresentaram maiores $(\mathrm{P}<0,05)$ valores de escore de empenamento do dorso (Tabela 3), diferindo significativamente das outras linhagens em cada ambiente de criação, enquanto que as linhagens LM1 e LM2 apresentaram os menores $(\mathrm{P}<0,05)$ valores nos ambientes de frango de corte e de estresse. Os escores das linhagens LF1, LF2, LM1 e LM2 foram maiores $(\mathrm{P}<0,05)$ no ambiente de pedigree em comparação à criação nos ambientes de frango de corte e de estresse.

Tabela 2 - Análise de variância para empenamento do dorso (ED) e da perna (EP) aos 28 dias de idade e peso vivo (PV) e rendimento da carcaça (RC) aos 42 dias de idade

Table 2 - Analysis of variance for back (BF) and leg feathering (LF) at 28 days-old and body weight (BW) and carcass yield (CY) at 42 days-old

\begin{tabular}{|c|c|c|c|c|c|}
\hline \multirow[t]{3}{*}{$\begin{array}{l}\text { FV } \\
S V\end{array}$} & \multirow[t]{3}{*}{$\begin{array}{l}\text { GL } \\
D F\end{array}$} & \multicolumn{4}{|c|}{$\begin{array}{c}\text { Característica } \\
\text { Trait }\end{array}$} \\
\hline & & ED & EP & PV & $\mathrm{RC}$ \\
\hline & & $B F$ & $L F$ & $B W$ & $C Y$ \\
\hline $\begin{array}{l}\text { Ambiente (A) } \\
\text { Environment (E) }\end{array}$ & 2 & $* *$ & $* *$ & $*$ & $* *$ \\
\hline $\begin{array}{l}\text { Linhagem (L) } \\
\text { Line }(L)\end{array}$ & 5 & $* *$ & $* *$ & $* *$ & $* *$ \\
\hline $\begin{array}{l}\text { A } \times \mathrm{L} \\
E \times L\end{array}$ & 10 & $* *$ & $* *$ & $* *$ & $* *$ \\
\hline $\mathrm{CV}(\%)$ & & 17,9 & 16,8 & 9,06 & 3,38 \\
\hline
\end{tabular}

${ }^{*} \mathrm{P}<0,01 ;{ }^{* *} \mathrm{P}<0,05$. 
As linhagens LF3 e LF4, em comparação às demais, apresentaram maior $(\mathrm{P}<0,05)$ escore para empenamento da perna (Tabela 4) nos três ambientes de criação. Os valores de escore para todas as linhagens no ambiente de pedigree foram maiores $(\mathrm{P}<0,05)$ em comparação à criação nos outros ambientes.

A partir dos resultados de empenamento, verificou-se superioridade das linhagens $L F 3$ e LF4 em relação às demais linhagens da linha fêmea (LF1 e LF2). Assim, no aspecto empenamento, as aves fêmeas das linhagens LF3 e LF4 deveriam ser selecionadas para utilização em cruzamentos, pois, como possuem melhor empenamento do dorso e da perna, os danos ocasionados durante a monta natural pelas unhas dos machos nessas fêmeas seriam menores.

Tem-se observado grande herdabilidade (75-80\%) em testes realizados para as características de empenamento, comprovando que a seleção em programas de melhoramento para aumento da cobertura de penas das aves

Tabela 3 - Médias de empenamento do dorso aos 28 dias de idade

Table 3 - Means for back feathering at 28 days-old

\begin{tabular}{lccc}
\hline $\begin{array}{l}\text { Linhagem } \\
\text { Line }\end{array}$ & \multicolumn{3}{c}{$\begin{array}{c}\text { Ambiente de criação } \\
\text { Rearing environment }\end{array}$} \\
\cline { 2 - 4 } & $\begin{array}{c}\text { Pedigree } \\
\text { Pedigree }\end{array}$ & $\begin{array}{c}\text { Frango de corte } \\
\text { Broiler }\end{array}$ & $\begin{array}{c}\text { Estresse } \\
\text { Stress }\end{array}$ \\
\hline LF1 & $7,20 \mathrm{Ba}$ & $6,21 \mathrm{Bb}$ & $5,95 \mathrm{Bb}$ \\
LF2 & $7,26 \mathrm{Ba}$ & $6,18 \mathrm{Bb}$ & $6,04 \mathrm{Bb}$ \\
LF3 & $7,90 \mathrm{Aa}$ & $7,60 \mathrm{Aa}$ & $7,13 \mathrm{Ab}$ \\
LF4 & $7,87 \mathrm{Aa}$ & $7,78 \mathrm{Aa}$ & $6,78 \mathrm{Ab}$ \\
LM1 & $7,10 \mathrm{Ba}$ & $5,12 \mathrm{Cb}$ & $5,16 \mathrm{Cb}$ \\
LM2 & $7,13 \mathrm{Ba}$ & $5,27 \mathrm{Cb}$ & $5,55 \mathrm{Cb}$ \\
\hline
\end{tabular}

Médias seguidas de letras maiúsculas (minúsculas) na mesma coluna (linha) diferem pelo teste Tukey $(\mathrm{P}<0,05)$.

Means followed by different capital (lower) letters within a column (row) differ by Tukey test $(P<0.05)$.

Tabela 4 - Médias de empenamento da perna aos 28 dias de idade

Table 4 - $\quad$ Means for leg feathering at 28 days-old

\begin{tabular}{lccc}
\hline $\begin{array}{l}\text { Linhagem } \\
\text { Line }\end{array}$ & \multicolumn{3}{c}{$\begin{array}{c}\text { Ambiente de criação } \\
\text { Rearing environment }\end{array}$} \\
\cline { 2 - 4 } & $\begin{array}{c}\text { Pedigree } \\
\text { Pedigree }\end{array}$ & $\begin{array}{c}\text { Frango de corte } \\
\text { Broiler }\end{array}$ & $\begin{array}{c}\text { Estresse } \\
\text { Stress }\end{array}$ \\
\hline LF1 & $4,88 \mathrm{Ba}$ & $4,74 \mathrm{Ba}$ & $4,48 \mathrm{Bb}$ \\
LF2 & $4,92 \mathrm{Ba}$ & $4,80 \mathrm{Ba}$ & $4,61 \mathrm{Bb}$ \\
LF3 & $5,62 \mathrm{Aa}$ & $6,00 \mathrm{Aa}$ & $4,92 \mathrm{Ab}$ \\
LF4 & $5,51 \mathrm{Aa}$ & $6,01 \mathrm{Aa}$ & $4,98 \mathrm{Ab}$ \\
LM1 & $4,70 \mathrm{Ba}$ & $4,64 \mathrm{Ba}$ & $4,71 \mathrm{Aa}$ \\
LM2 & $4,80 \mathrm{Ba}$ & $4,70 \mathrm{Ba}$ & $4,80 \mathrm{Aa}$
\end{tabular}

Médias seguidas de letras maiúsculas (minúsculas) na mesma coluna (linha) diferem pelo teste Tukey $(\mathrm{P}<0,05)$.

Means followed by different capital (lower) letters within a column (row) differ by Tukey test $(P<0.05)$. híbridas é viável e pode diminuir a desvalorização de carcaças em abatedouros, ocasionada pela presença de ferimentos e arranhões (Leeson \& Walsh, 2004a; Mendes, 2001).

Os resultados encontrados neste trabalho corroboram os apresentados por Leeson \& Walsh (2004b), que observaram diferenças de empenamento entre linhagens de frangos de corte. Mendes (2001), por sua vez, observou em linhagens de frangos de corte piora do escore de empenamento com o aumento da densidade de alojamento, como observado neste estudo nos ambientes de criação de frango de corte e nos de estresse.

Leeson \& Walsh (2004b) relacionaram as diferenças no processo de empenamento corporal das aves à temperatura do ambiente no qual as aves são alojadas, ou seja, os processos de empenamento em uma mesma linhagem sofrem influência da temperatura do ambiente de alojamento, fato que justifica os resultados encontrados nesta pesquisa.

Os pesos vivos das aves das linhagens LM1 e LM2 aos 42 dias de idade, em todos os ambientes avaliados, foram maiores $(\mathrm{P}<0,05)$ que os obtidos com as outras linhagens (Tabela 5), ao passo que as linhagens LF3 e LF4 apresentaram menores $(\mathrm{P}<0,05)$ pesos vivos em comparação às outras linhagens nos ambientes de criação de frango de corte e estresse.

Aos 42 dias de idade, as linhagens LF1, LF2, LM1 e LM2 criadas nos ambientes de pedigree e de frango de corte apresentaram pesos vivos superiores ao divulgado no Manual de Manejo (2004) para o híbrido comercial (2.474 g), resultado de cruzamentos entre essas linhagens, enquanto as linhagens LF3 e LF4 tiveram pesos vivos maiores apenas quando criadas no ambiente de pedigree. Em todas as linhagens, os menores pesos vivos aos 42 dias, em comparação ao híbrido comercial, foram obtidos no ambiente de estresse.

Essas diferenças entre os pesos vivos das linhagens estudadas são reflexo da pressão de seleção adotada nos programas de melhoramento, pois as linhagens LM1 e LM2 (linha macho) sofreram maior pressão de seleção para peso vivo, expressando mais esta característica em comparação às demais linhagens (linha fêmea), que passaram por menor pressão de seleção para peso vivo.

A inferioridade do peso vivo apresentada pelas linhagens criadas no ambiente de estresse, em comparação ao peso vivo do híbrido comercial e aos outros ambientes de criação, demonstra influência ambiental no desempenho das aves. A literatura é vasta em trabalhos nos quais o desempenho das aves é afetado negativamente em ambientes com condições térmicas fora da zona de conforto, haja vista a redução no consumo de alimento e a dificuldade de perda de calor corpóreo (Cheng \& Muir, 2005; Flock et al., 2005). 
Tabela 5 - Médias de peso vivo (g) aos 42 dias de idade obtidas com as linhagens em diferentes ambientes de criação

Table 5 - Means for body weight ( $g$ ) at 42 days-old according to lines and rearing environments

\begin{tabular}{lccc}
\hline $\begin{array}{l}\text { Linhagem } \\
\text { Line }\end{array}$ & \multicolumn{3}{c}{$\begin{array}{c}\text { Ambiente de criação } \\
\text { Rearing environment }\end{array}$} \\
\cline { 2 - 4 } & $\begin{array}{c}\text { Pedigree } \\
\text { Pedigree }\end{array}$ & $\begin{array}{c}\text { Frango de corte } \\
\text { Broiler }\end{array}$ & $\begin{array}{c}\text { Estresse } \\
\text { Stress }\end{array}$ \\
\hline LF1 & $2601,44 \mathrm{Ba}$ & $2602,00 \mathrm{Ba}$ & $1753,73 \mathrm{Bb}$ \\
LF2 & $2554,26 \mathrm{Ba}$ & $2604,25 \mathrm{Ba}$ & $1782,86 \mathrm{Bb}$ \\
LF3 & $2550,26 \mathrm{Ba}$ & $2402,00 \mathrm{Cb}$ & $1580,29 \mathrm{Cc}$ \\
LF4 & $2563,45 \mathrm{Ba}$ & $2402,50 \mathrm{Cb}$ & $1602,97 \mathrm{Cc}$ \\
LM1 & $3096,20 \mathrm{Aa}$ & $2800,50 \mathrm{Ab}$ & $1989,73 \mathrm{Ac}$ \\
LM2 & $3087,19 \mathrm{Aa}$ & $2801,00 \mathrm{Ab}$ & $1953,40 \mathrm{Ac}$ \\
\hline
\end{tabular}

Médias seguidas de letras maiúsculas (minúsculas) na mesma coluna (linha) diferem pelo teste Tukey $(\mathrm{P}<0,05)$.

Means followed by different capital (lower) letters within a column (row) differ by Tukey test $(P<0.05)$

As Figuras 1 e 2 representam adequadamente essa condição ambiental fora da zona de conforto que ocorreu com freqüência durante a criação das linhagens no ambiente de estresse, o que, associado às condições de manejo diferenciadas (alta densidade de alojamento e quantidade inferior de EM e proteína na dieta), resultou em menor desempenho em relação à criação nos ambientes de pedigree e de frango de corte. Moreira et al. (2004) observaram piora no desempenho de linhagens de frangos de corte com o aumento da densidade de alojamento.

Nos ambientes frango de corte e de estresse, as linhagens LM1 e LM2 apresentaram (Tabela 6) maiores $(\mathrm{P}<0,05)$ rendimentos da carcaça em comparação às demais linhagens. Todas as linhagens apresentaram maiores $(\mathrm{P}<0,05)$ rendimentos de carcaça quando criadas no ambiente de criação de frango de corte em comparação aos demais ambientes de criação. O menor rendimento foi obtido com a linhagem LF4 criada no ambiente de estresse.

Os rendimentos de carcaça das linhagens obtidos no ambiente de frango de corte foram maiores que o do híbrido comercial apresentado no Manual de Manejo (2004), de $71,4 \%$, e que o obtido por Moreira et al. (2004), de 70,37\%, todavia, foram menores que o rendimento médio do híbrido comercial obtido por Mendes et al. (2004) (82,40\%). Todas as linhagens quando criadas nos ambientes de pedigree $\mathrm{e}$ de estresse apresentaram rendimentos de carcaça eviscerada menores que o do híbrido comercial apresentado no Manual de Manejo (2004) e na literatura.

Esses resultados comprovam as modificações decorrentes dos processos de seleção na conformação de carcaça da linhagem híbrida resultante do cruzamento das linhagens de avós estudadas. Essas modificações, associadas às melhorias das condições ambientais e de manejo, têm
Tabela 6 - Rendimento (\%) de carcaça aos 42 de idade obtidos com as linhagens em diferentes ambientes de criação

Table 6 - Means for carcass yield (\%) at 42 days-old according to lines and rearing environments

\begin{tabular}{lccc}
\hline $\begin{array}{l}\text { Linhagem } \\
\text { Line }\end{array}$ & \multicolumn{3}{c}{$\begin{array}{c}\text { Ambiente de criação } \\
\text { Rearing environment }\end{array}$} \\
\cline { 2 - 4 } & $\begin{array}{c}\text { Pedigree } \\
\text { Pedigree }\end{array}$ & $\begin{array}{c}\text { Frango de corte } \\
\text { Broiler }\end{array}$ & $\begin{array}{c}\text { Estresse } \\
\text { Stress }\end{array}$ \\
\hline LF1 & $69,73 \mathrm{Ab}$ & $71,90 \mathrm{Ba}$ & $66,67 \mathrm{Bc}$ \\
LF2 & $69,58 \mathrm{Ab}$ & $72,11 \mathrm{Ba}$ & $67,01 \mathrm{Bc}$ \\
LF3 & $69,29 \mathrm{Ab}$ & $72,14 \mathrm{Ba}$ & $66,93 \mathrm{Bc}$ \\
LF4 & $69,29 \mathrm{Ab}$ & $71,51 \mathrm{Ba}$ & $64,27 \mathrm{Cc}$ \\
LM1 & $70,64 \mathrm{Ab}$ & $75,22 \mathrm{Aa}$ & $69,96 \mathrm{Ab}$ \\
LM2 & $70,67 \mathrm{Ab}$ & $74,07 \mathrm{Aa}$ & $69,94 \mathrm{Ab}$ \\
\hline
\end{tabular}

Médias seguidas de letras maiúsculas (minúsculas) na mesma coluna (linha) diferem pelo teste Tukey $(\mathrm{P}<0,05)$.

Means followed by different capital (lower) letters within a column (row) differ by Tukey test $(P<0.05)$.

ocasionado evolução do rendimento de carcaça dessa linhagem nos últimos anos.

Segundo Nääs et al. (2001), as aves encontram condições perfeitas para expressão de suas melhores características quando dentro da zona de conforto, que está diretamente relacionado a ambiente térmico ótimo. Neste sentido, as variáveis morfométricas e zootécnicas das aves criadas no ambiente de pedigree sofreram menor influência ambiental e tenderam a ser superiores àquelas criadas nos ambientes de frango de corte e de estresse.

Assim, a interação genótipo $\times$ ambiente deve ser considerada em programas de melhoramento de aves por facilitar a avaliação da influência ambiental e garantir a seleção de genótipos superiores em cada ambiente de criação.

\section{Conclusões}

Existem respostas diferenciadas das linhagens de avós de frangos de corte ao ambiente de criação utilizado. $\mathrm{O}$ ambiente de criação de estresse foi considerado inadequado em comparação aos ambientes de pedigree e de frango de corte.

As linhagens da linha macho apresentaram melhor desempenho quando considerados o peso vivo e o rendimento de carcaça, ao passo que as linhagens da linha fêmea apresentaram melhor desempenho quando consideradas as características de empenamento do dorso e da perna.

\section{Literatura Citada}

BARBOSA FILHO, J.A.D. Avaliação do bem-estar de aves poedeiras em diferentes sistemas de produção e condições ambientais, utilizando análise de imagens. 2004. 123p. Dissertação (Mestrado em Agronomia) - Escola 
Superior de Agricultura Luiz de Queiroz, 2004. Disponível em <http://www.teses.usp.br/ teses/disponiveis/11/11131/tde11052005-44156/publico/jose.pdf>. Acesso em: 01/08/2005.

BARBOSA FILHO, J.A.D.; SILVA, M.A.N.; SILVA, I.J.O. et al. Egg quality in layers housed in different production systems and submitted to two environmental conditions. Brazilian Journal of Poultry Science, v.8, p.23-28, 2006.

CHENG, H.; MUIR, W.M. The effects of genetic selection for survivability and productivity on chicken physiological homeostasis. World's Poultry Science Journal, v.61, p.383397, 2005.

FLOCK, D.K.; LAUGHLIN, K.F.; BENTLEY, J. Minimizing losses in poultry breeding and production: how breeding companies contribute to poultry welfare. World's Poultry Science Journal, v.61, p.227-237, 2005.

FURLAN, R.L.; MACARI, M. Termorregulação. In: MACARI, M.; FURLAN, R.L.; GONZALES, E. (Eds.). Fisiologia aviária aplicada a frangos de corte. 1.ed. Campinas: Fundação Apinco de Ciência e Tecnologia Avícolas, 2002. p.209-230.

JONES, T.A.; DONNELLY, C.A.; DAWKINS, M.S. Environmental and management factors affecting the welfare of chickens on commercial farms in the United Kingdom and Denmark stocked at five densities. Poultry Science, v.84, p.1155-1165, 2005.

LEESON, S.; WALSH, T. Feathering in commercial poultry: feather growth and composition. World's Poultry Science Journal, v.60, p.42-51, 2004a.

LEESON, S.; WALSH, T. Feathering in commercial poultry: factors influencing feather growth and feather loss. World's Poultry Science Journal, v.60, p.52-63, 2004b.

MACARI, M.; FURLAN, R.L.; MAIORKA, A. Aspectos fisiológicos e de manejo para manutenção da homeostase térmica e controle de síndromes metabólicas. In: MENDES, A.A.; NÄÄS, I.A.; MACARI, M. (Eds.). Produção de frangos de corte. 1.ed. Campinas: Fundação Apinco de Ciência e Tecnologia Avícolas, 2004. p.137-155.

MANUAL DE MANEJO DE FRANGOS AGROSS [2004]. Disponível em: <http://www.agroceresross.com.br/servlet/ navSrvt?cmd=listPublicacaoFrango\&id=47>. Acesso em: 01/09/ 2005 .
MENDES, A.A. Rendimento e qualidade da carcaça de frangos de corte. In: CONFERÊNCIA APINCO 2001 DE CIÊNCIA E TECNOlogia AVÍCOlAs, 2001, Campinas. Anais... Campinas: Fundação Apinco de Ciência e Tecnologia Avícolas, 2001. v.2, p.79-99.

MENDES, A.A.; MOREIRA J.; OLIVEIRA, E.G. et al. Efeitos da energia da dieta sobre desempenho, rendimento de carcaça e gordura abdominal de frangos de corte. Revista Brasileira de Zootecnia, v.33, p.2300-2307, 2004.

MOREIRA J.; MENDES, A.A.; ROÇA, R.O. et al. Efeito da densidade populacional sobre desempenho, rendimento de carcaça e qualidade da carne em frangos de corte de diferentes linhagens comerciais. Revista Brasileira de Zootecnia, v.33, p.15061519, 2004.

NÄÄS, I.A.; MIRAGLIOTTA, M.Y.; ARADAS, M.E.C. et al. Controle e sistematização em ambientes de produção. In: SILVA, I.J.O. (Ed.). Ambiência na produção de aves em clima tropical. 1.ed. Piracicaba: FUNEP, 2001. v.1, p.165-200.

STATISTICAL ANALYSIS SYSTEM - SAS. SAS OnlineDoc ${ }^{\circledR}$ versão 8.02. Disponível em: <http://www.id.unizh.ch/software/ unix/statmath/sas/sasdoc/stat/index.htm> Acesso em: 04/08/2005.

SILVA, M.A.N.; SILVA, I.J.O.; PIEDADE, S.M.S. et al. Resistência ao estresse calórico em frangos de corte de pescoço pelado. Revista Brasileira de Ciência Avícola, v.3, p.27-33, 2001.

SOUZA, E.M.; MICHELAN FILHO, T. Genética avícola. In: MENDES, A.A.; NÄÄS, I.A.; MACARI, M. (Eds.). Produção de frangos de corte. Campinas: Fundação Apinco de Ciência e Tecnologia Avícolas, 2004. p.23-35.

THOM, E.C. Cooling degree: dayair conditioning, heating, and ventilating. Transaction of the American Society of Heating, v.55, p.65-72, 1958.

YAHAV, S.; SHINDER, D.; TANNY, J. et al. Sensible heat loss: the broiler's paradox. World's Poultry Science Journal, v.61, p.419-434, 2005. 